\title{
The Growth of Growth
}

\author{
STANLEY M. GARN \\ Center for Human Growth and Development, University of Michigan, Ann \\ Arbor, Michigan 48109
}

\section{KEY WORDS History, Growth research, Longitudinal studies}

\begin{abstract}
Over a 40-year period, 1940 through the present, human growth research has increased from a minimal to a major part of physical anthropology. Such research, originally conducted at the major American growth centers, has become more diverse and more specialized, extending to National Probability Samplings, nutritional surveys, studies of twins, investigations restricted to the craniofacial complex, and studies of the growth and development of various primate species. Besides extending knowledge of growth and development in general and control mechanisms in particular, there has been major feedback into physical anthropology affording far greater understanding of human variability, of taxonomic differences, and of changes previously believed to be phylogenetic in nature. To the larger extent, all physical anthropologists have some degree of growth awareness.
\end{abstract}

Earnest Albert Hooton took a dim view of growth studies. He took a dim view of many things. "Growth" research, he once observed to me over jasmine tea and shortcake, "merely shows that older children are bigger."

In part this was the Harvard-intellectual stance, the ability to see the dimmer side of anything. In part this was Hooton's preferred position, a blend of misogyny and misanthropy. In part this also reflected what most physical anthropologists knew about growth research, circa 1940.

To be sure, Harvard had a major American longitudinal growth study, well known for radiographic investigations. But that was across in Boston. At the Massachusetts General Hospital Fritz Talbot (the father) and Nathan Talbot (the son) had made major contributions on the physiological and endocrine determinants of growth. But that was also across the Charles, and that was "medicine." Physical anthropologists had not yet discovered the basal metabolic rate or creatinine or the nutritional determinants of growth and form.

The war years brought new connections and new opportunities to most of us, close at home at the Harvard Physiological Laboratories, and further away at Wright Patterson Air Force Base near Dayton, Ohio. We learned that there was more to measurement than anthro- pometry, that exhaled air showed more than lung capacity, and that urine was almost too valuable to void.

After the war, growth research emerged as far more than just documentation of gross dimensional changes. And Hooton began to change his earlier myopic views. Growth research emerged as a source of employment for physical anthropologists which increased its respectability to Hooton. Such contributions as Gordon 'T. Bowles's historical documentation of secular change ("New types of old Americans at Harvard . . .") and Gabriel W. Lasker's confirmation of changes in Chinese migrants to the United States also put growth research into a new perspective, using the familiar anthropometric framework. Besides, Wilton M. Krogman had built a reputation as a "growth" man at Chicago, and it was not congenial to Hooton that Chicago should lead Harvard in any intellectual respect.

So Hooton let me offer a growth course at Harvard, drawing on my work at the Forsyth Dental Infirmary in Boston, and bringing anthropology students into contact with both skeletal and dental growth. Edward I. Fry was one of the first graduates of that course (how he objected to learning the details of handwrist ossification!). Paul T. Baker was another member of that first class. And that Harvard growth course was continued, after I left for 
the Fels Research Institute, by Edward E. Hunt Jr.

Hooton had come to the conclusion that it was important to discover why children grow.

\section{SOME PEOPLE IN HUMAN GROWTH}

Even in 1950 there were rather few physical anthropologists actively involved in studies of human growth. So small was their number that they could meet around a dinner table, and they did. Since the number was small, there was no age-grading at these ad hoc "growth" meetings. Since there were few graduate students to peddle in those days, job opportunities as well as research findings were freely discussed.

Bill Krogman, of course, had an international reputation as a scholar of encyclopedic breadth, and his reputation attracted foreign students to our shores. He also proved to be a raconteur of considerable skill, and a limerickcollector (with an incredible repertory). William W. Greulich evidenced a surprising interest in such nonanatomical growth problems as the secular change and the combined effects of secular change and migration. He possessed a courtly Old-World politeness.

Howard V. Meredith also participated in these at-lunch sessions, and in that way I came to discover how much of the Stuart-Stevenson "growth" norms derived from Meredith and Iowa. Many clinicians have viewed the "Iowa" norms and the "Boston" norms as separate, not realizing that the apparently longitudinal Boston-Harvard values were based in part on semilongitudinal Iowa City school data.

At these impromptu sessions, Earle L. Reynolds also made his appearance, and being closer to me in age we became closer correspondents and visited each other as the opportunities allowed. Earle had mastered the writer's habit of setting aside a portion of each day for writing, which helps to explain his productivity. It is a habit worth emulating, and I pass it on, with appreciation.

\section{SOME PEOPLE FROM ABROAD}

Closer to me still, in age and status, were Melvin J. Baer and James A. Gavan, so we interacted more at the annual meetings. Melvin Baer was established in the MerrillPalmer School in Detroit, in an office complete with a fireplace and a lavatory-magnificent compared with my fifth-floor table in the bone lab at the Peabody Museum, inherited from Lloyd Warner.
Abroad, James M. Tanner was building a reputation and we encouraged him to visit the United States again. In 1950 I had the opportunity to invite him to the Forsyth, just before the annual meeting of the American Association of Physical Anthropologists. The speech he gave to our dental interns and dental hygienists was memorable because 60 dental hygienists $(60)$ fell in love with him at once.

Two other British colleagues were building reputations in human growth and development, and both migrated to the United States for prolonged periods of time. Roy M. Acheson developed a method of skeletal growth assessment, then spent years as an epidemiologist at Yale. Frank Falkner migrated to Louisville and became the Director of the Louisville Twin Study, then the chairman of pediatrics there. After a stint at the National Institutes of Health he became the second director at the Fels Research Institute. Only after he came to the University of Michigan did I discover that he had been an accomplished pianist, and the extent of his activities as a racing-car driver and (later) racing judge.

Kalevi Koski, after an internship at the Forsyth, returned to Finland and was active in founding the Finnish Growth Study. It was a pleasure to be invited to contribute to the Festschrift in his honor, just recently published.

\section{THE PEOPLING OF THE GROWTH STUDIES}

The founders of the longitudinal growth studies at Denver, Harvard, and the Fels Institute were trained in clinical medicine and the studies were started (in the early days) by clinicians. This gave credibility to the studies and reassurance to the parents of participants. Junior staff members were frequently recruited from the nursing profession, a practice that was equally useful in maintaining relations with the parents and in enrolling new participants.

As the Fels Institute expanded and planned the modern new building that houses the Fels today, Lester W. Sontag broke with the tradition of a medically trained senior staff. This was necessary for the addition of psychologists (as compared with psychiatrists), for biochemists, and (upon departure of Meinhard Robinow) for growth-oriented physical anthropologists.

Earle Reynolds was brought from Wisconsin as the first physical anthropologist to serve on the senior staff at the Fels. I was his successor, 
in 1952, after Earle decided to remain in Japan in the study of Hiroshima and Nagasaki atombomb victims. (And Alex F. Roche became my successor in turn when I left for the University of Michigan in 1968.)

Since Antioch College did not have graduate students, I began the practice of bringing in graduate assistants from other universities. Laura Newell-Morris, Batsheva Bonne, and Patricia Schwager Gindhart are among those who have gone on to professional rank in physical anthropology. For 16 years, or nearly, we operated a de facto training program at the Fels with students from Arizona, Colorado, Indiana, Pensylvania, and Washington State (among other places).

Dr. Samuel Selby was hired as the pediatrician at the Fels in 1952, coincident with my becoming chairman of the Physical Growth Department there. Sam Selby had years of experience in South Africa and greeted such visitors as Ronald Singer as old friends. But it turned out that Selby was a Hooton product too, circa 1917, and he managed to quiz me on the rudiments of physical anthropology as taught to him then. Sam had also known Ashley Montagu in London, early in Sam's career as a pediatrician, and he described Ashley's mother to my mother, to my (and her) delight.

One person was shared by the Denver, Harvard, and Fels groups and that was S. Idell Pyle, of Greulich-Pyle fame and an outstanding contributor on her own. Before computerstorage of data she maintained an incredible mental file of maturational features and variations in ossification timing and sequence. She knew the frequency of the hamate-capitate sequence or order, and other atypical sequences, and she trained willing workers in the detailed center-by-center method most effectively. So trained, Dr. Arthur B. Lewis (our Fels orthodontist) achieved a 0.998 sixmonth replicability in bone-age assessment, proof to me of the inherent reliability of the Gruelich-Pyle method when meticulously applied.

\section{PARTICIPANTS IN LONGITUDINAL STUDIES}

Participants in the longitudinal growth studies gave remarkably much of their time to the study and cooperated in a variety of ways. Besides annual and semiannual visits, which often occupied a full day, there were questionnaires to fill out, and home visits, dietary records to keep, and urine collections (some for a full week and more). Commitment to a longitudinal growth study was a commitment on both sides, and the staff of the studies endeavored to keep the participants interested, cooperative, and coming. There were dropouts, of course, as families moved away, and temporary absences (particularly in the early adolescent years). For these reasons the subject number at later examinations fell below the starting $n$, a severe handicap in data analysis for the smaller studies. The extremes of fatness tended to be less regular in attendence, a phenomenon I have also observed in such longitudinal programs as the National Collaborative Perinatal Project (NCPP) of the National Institute of Neurological and Communicative Diseases and Stroke (NINCDS).

The regular physical examinations were an important incentive in the early days as were special examinations arranged for school, college, and camp entrance requirements. There was need to avoid competition with the family physicians, of course, but they had the privilege of requesting special diagnostic tests and radiographs for participants who were their patients. February was the peak month for such extra business, in the wet and cold weather of southwestern Ohio, and each February there were many requests for hearing tests which kept me and the MAICO test equipment occupied.

At the Fels we had birthday gifts, and "halfbirthday" gifts, stored in a special closet and the children and adolescents could take their pick. Keeping the supply full, and up to date, required regular trips to wholesale toy merchants. My graduate training in physical anthropology had not provided background in this professional activity, and I was glad to introduce my graduate assistants to volume purchasing, toy selection, and discounts.

I was impressed then, and remain impressed now, with the extent of subject cooperation and their efforts to complete their regular visits within the tolerance times, which were necessarily more elastic for those in college and beyond. Some came from hundreds of miles to make their annual birthday visits. I have the warmest feelings for one Fels participant who arrived the day after Christmas with an apology for being late. He had flown up from the South Pole just to make his annual visit.

While some participants were bored with their participation and dropped out as soon as they could, others were fascinated with the variety of tests and measurements and motivated to biomedical and behavior-science 
careers. We became college-entrance advisors and career-counselors in a way, and some few of our participants have since become colleagues. More than once I have been questioned (after lectures on growth) about the participants in longitudinal studies with former participants (subjects) sitting in the audience.

\section{SOCIOECONOMICS AND GROWTH}

Reviewing the publications of the major American growth studies in the 1940s and 1950 s it would seem that the major American growth studies ignored the socioeconomic status (SES) of their subject "populations." Reviewing the papers and publications that had to do with "growth" it would also appear that the socioeconomic determinants of increase in size and maturational timing were accorded scant attention. Phenomena that we know now as socioeconomic in origin were then accorded numerous other explanations.

The major American growth studies did not really ignore the SES of their "populations" or individual families under study. In fact, in the early data-gathering phases a remarkable amount of socioeconomic detail was accumulated-even to counting books on the shelves and pictures on the walls. But socioeconomic rankings of indexes were rarely included in the published reports so that it is difficult now to reassess the relative economic positions of the Boston, Berkeley, Denver, Brush Foundation, and Fels samples.

The directors of these studies were not unaware of social class and income as factors affecting human growth but there were reasons why such measures were ignored in the reports. Most of the samples were too small to partition along socioeconomic lines. Besides, the families were in the process of social mobility. Lester Sontag, Harold Stuart, and Al Washburn viewed their subjects as a population of people and Sontag, in particular, was more interested in the interrelationships of variables than in comparisons with other studies.

So the Boston, Berkeley, Brush, Denver, and Fels populations have all been described in secondary and tertiary sources as "middle class," which was scarcely the case. Socioeconomic differences between the participants in the Brush Foundation Study in Cleveland and the second Harvard Longitudinal Study are rarely mentioned today.

It is interesting, therefore, to read the "explanations" given for some of the differ- ences between populations studied. The Berkeley boys and girls are cited as exemplifying the benefits of California sunshine. A slight delay in maturation and in some ossification centers in the Denver sample is attributed to the mile-high elevation of Denver. Great differences between the Boston sample and the Brush Foundation sample are only casually mentioned even though the boys and girls from the Cleveland suburbs remain the tallest and earliest maturing - even after a lapse of 40 years!

It is intriguing, therefore, that the Bone Age Standards most extensively used are derived from the most favored (Cleveland) sample and that, despite the secular trend, size and growth and development elsewhere in America have not caught up with the Brush Foundation boys and girls studied decades ago.

\section{THE PRODUCTION OF NORMS AND STANDARDS}

The longitudinal growth studies of the 1930s and 1940s had two major directions, both of which continue to a variable extent today. One was primarily descriptive, "to see how children grow." The other had to do with the development of norms or standards for size, skeletal development, and sexual maturation.

The descriptive studies carried excitement when rather little was known about human growth. It was truly exciting to discover how menarche related to statural attainment and how stages of breast, areola, axillary, and pubic hair development fitted into the dimensional scheme. Earle Reynolds's papers, from the Fels, are the basis for systems of sexual maturation still in use (though Earle was especially cognizant of different individual sequences of maturation). However, it is not exciting when contemporary authors merely recapitulate size-for-age data or maturational stages for still another sample of boys and girls.

The "growth" standards from the Brush Foundation, Denver, Fels, and Harvard (Boston) studies found early and immediate clinical use and were extensively used in population studies and nutritional surveys in the postwar period. Pediatricians trained in the East used the "Boston" standards, and those trained in the Midwest employed the "Iowa" standards, quite unaware that both made extensive use of the same Iowa City schoolchildren as mentioned earlier. Pediatric radiologists used the Gruelich-Pyle radiographic standards derived from the Brush Foundation data also unaware of the 
economically favored nature of the high SES Brush Foundation sample.

In their times the Brush Foundation, Denver, Fels, and Harvard investigators worked upon the basic assumption that the growth and development of an economically favored sample would provide an indication of optimal growth and maturation against which the growth of other children could be measured. I am in agreement with this notion, though noting that the participants in different studies were not equally favored with respect to parental education, income, or occupation. But when it came to the development of the "New Growth Charts" a different point of view obtained. There was emphasis on an attainable average and hence a National Probability Sampling, and the use of data from the National Center for Health Statistics, and the National Health and Nutrition Examination Studies (NHANES).

The "New Growth Charts" for height and weight and weight-for-height therefore differ in concept from the Harvard, Fels, Denver, and Iowa norms. They are based in large part on a National Probability Sampling and an infinitely larger subject $n$ than Iowa City and Boston. They are not that different, at the 50th percentiles, however, because the Boston children and the Iowa City schoolchildren of years before were not drawn from the economic elite. There are great differences at the outer percentiles, however, in part because of the far larger sample used. And the "New Growth Charts" incorporate approximately $15 \%$ of black boys and girls, whereas the Brush, Denver, Fels, and Harvard samples were exclusively white.

\section{NUTRITION AND GROWTH}

The longitudinal growth studies of the prewar era incorporated dietary records and measures of serum and urinary vitamins into their massive data accumulations. This was slow work in the precomputer era, and before automated laboratory methods were available. One can imagine the analytical labor that 7-day dietary records entailed and that repeated blood and urine specimens required. The results, analyzed and published, gave new ranges of normality for the biochemical measures, and new indications of actual intake of calories and nutrients.

Within the confines of the growth studies, however, nutrition and growth had not come together. It was difficult to say whether bigger children ate more because they were bigger or whether they were bigger because they ate more (a problem that still exists). But as the anthropometric approaches of the growth studies were applied to other-world populations, and as the biochemical determinations were also made, nutrition and growth came together suddenly, beneficially, and dramatically. With U.S. financial and expert support nutritional surveys were mounted in a great many countries, from Thailand to Ethiopia to Peru and the Central American nations. As might have been expected, dietary insufficiency and small size clearly went together. Anthropologists could no longer assume that the small people of the world were simply genetically small. D.F. Roberts's brilliant observations on temperature and body size suddenly assumed a different, nutritional explanation.

When he organized INCAP (The Institute of Nutrition of Central America and Panama) Nevin Scrimshaw included physical anthropology as well as nutrition and biochemistry and parasitology in the tables of the organization. Soon INCAP developed the parallel-villages approach, giving nutritional supplementation to one village, improved sanitation to another village, and only minimal medical care to a third village. In this sophisticated way nutrition could be explored in relation to growth and especially the growth of the preschool child.

Such experimental designs, such approaches, and such analyses put a new, largely nutritional face on human growth studies. In a way they doomed the traditional, normative, see-children-grow approaches. Whether it was Incaparina (the INCAP-developed cereal supplement in Central America) or a zincprotein supplement in cookie form used in Iran, there were new opportunities to investigate nutrition and growth directly and experimentally. The WIC supplementation program in the United States sponsored by the Department of Agriculture, is another such example nationwide in character and devoted to more than descriptive data. From the Johnson Administration on, our governmental posture has favored direct approaches and intervention studies-and so there has been relatively less money for the study of "normal" growth in putatively normal boys and girls.

Of course, nutritional supplementation is also difficult to evaluate, what with the tendency of human beings to remain isocaloric, and with diversion of the supplemental calories to the parental pocket. Many programs of supplementation have been with- 
out demonstrated effectiveness on growth whether directed to infants and children or to pregnant women. Except in the metabolic ward, perhaps, or by comparing the growth of fat children and those who are lean, what is intuitively obvious is not so easy to cure, ameliorate, or reverse in the field.

\section{BODY COMPOSITION AND GROWTH}

At mid-century, human body composition emerged as a new unifying interest that bridged and encompassed many different biomedical disciplines. it was exciting to share techniques and approaches to the twocomponent model with biochemists and physiologists and surgeons. To a large extent this excitement was the achievement of Joseph Brožek, who commanded respect among clinicians, laboratory workers, and engineers alike and who held multiple credentials as a physiologist, physical anthropologist, and physiological psychologist.

Since destructive (take-apart) analyses of body composition were necessarily limited when it came to human beings, nondestructive and noninvasive approaches were in order. Growth studies (Denver, Harvard, and Fels) had ready-made compartmental data in the form of radiographic measurements of outer fatness, of muscle-diameters, and of skeletal widths. Data on basal oxygen consumption and creatinine excretion could be employed as well, in the search for direct and substractive estimates of fat and lean accomplished in vivo.

It was intriguing to try other approaches including fatfold ("skinfold") measurements and underwater weighing. I was at first skeptical of fatfolds and set forth to compare them with radiogrammetric measurements. In so doing I discovered the variable compressibility of the double-folds, which Brožek and Mori later extended, and the surprisingly high comparability of fatfolds and radiogrammetric measurements. Soon fatfolds became part of growth anthropometry, and nutritional anthropometry, both.

So in 1956 Brožek called a conference on just this subject. One major result was the specifications for the constant-pressure fatfold calipers that we all use now. The final production models were completed by Dr. K.O. Lange of Lexington, Kentucky, in the converted henhouse behind his home that became a notable engineering facility. (Physical anthropologists may remember some of the anthropometric equipment Lange designed, including the original Forsyth "Facometer" of 1950, and lowcost anthropometers. Trained in aeronautical engineering and in meterology, he had even served as chairman of the Anthropology Department for a while.)

Since we could measure fatness, if not the exact fat weight (FW) or the weight of obesity tissue, it was then practicable to investigate the effect of fatness on growth. It was soon apparent that fat boys and girls grew at a greater rate, that they were taller, and that they matured earlier, often years earlier. While the ability to accomplish body composition analy. ses in the mass eluded us (and eludes us still), the ability to measure fatness was a quantum addition to human growth studies. It is a poor student now who tries to study "growth" without attention to body fat.

\section{DENTOFACIAL GROWTH}

The Founding Fathers of the three major longitudinal growth studies were supportive but not enthusiastic when it came to dentofacial growth and development. Neither Sontag nor Stuart nor Washburn had strong interests in the growth of the face and teeth and jaws. But they scheduled dental examinations for tooth emergence, they were receptive to the making of dental impressions, and even to the jaw and skull radiographs (and later analyses based on accumulated radiographic data).

Meinhard Robinow was the pediatrician at the Fels Research Institute in the prewar years, and he published (among other things) a definitive study on deciduous tooth emergence. That study appeared in time for my undergraduate thesis in 1942 and it was the beginning of a long-term relationship that continues to the present time. By 1940 Arthur B. Lewis had joined the Fels staff on a day-aweek basis, supervising the dental cast program and the collection of jaw and skull radiographs. Arthur Lewis continued his association with the Fels, devoting his Wednesdays to research (instead of playing golf), and he continues his activities, still.

Coming to the Fels in 1952, I was delighted with the opportunity to work with Arthur Lewis, and we began studies on tooth formation, tooth emergence, crown size, and jaw growth. He was not overly possessive of the radiographic and cast collections and allowed their use by C.F.A. Moorrees and E.E. Hunt, Jr., in the preparation of their tooth-formation standards. He also put me to work reviewing manuscripts for the Angle Orthodontist, which he edited, with the assistance of his wife.

I needed help in dental data analysis, and acquired such help in various ways. Laura Newell and Batsheva Bonne came to me as advanced graduate students, and I proudly claim 
both of them as my students too. Rose Kerewsky was the mother of one of my Antioch students, and so I acquired her as kind of a teaching award. Lina Landkof was Harry Jerison's mother-in-law and so I got help on the dental analyses and an early glimpse into Jerison's outstanding work on the evolution of the brain.

By the time Harry Israel joined us to advance studies on alveolar bone growth and dental aging (and his own contributions on continuing enlargement of the skull and jaws), specialized studies on dentofacial growth had emerged. Bill Krogman had his Philadelphia growth study, the first to incorporate computer-assisted digitization of craniofacial landmarks. Bhim Sen Savara had his Oregon growth study and Robert E. Moyers (then at Torontol had started the Burlington, Ontario growth study, later then to translate his interests to the University of Michigan, and to found the longitudinal study there.

In covering this time period, roughly four decades, I am impressed with the great expansion of dentofacial growth studies and how important they have become to physical anthropology. Back in 1952, when I wrote "The Education of the Physical Anthropologist," I quite underestimated the future of such studies and their potential for expansion. Then, tooth measuring was a minor part of physical anthropology and (I thought) unlikely to grow. Little more than a decade later, the National Institute of Dental Research bought into the Washington Primate Center and was instrumental in bringing Daris R. Swindler there. Now my colleagues James A. McNamara and David S. Carlson have longitudinal dentofacial data on Macaca mulatta with graduate students and postdoctoral fellows making histological preparations and EMG studies. For many others the analysis of dental dysmorphogenesis and craniofacial malformations has become a lifetime career, using the perspective of putatively normal craniofacial growth as a point of departure. What a difference from the days when dental development was a very small and unappreciated part of human growth studies.

\section{THE COMPUTER REVOLUTION}

The major longitudinal growth studies accumulated vast amounts of data in the course of yearly and half-yearly examinations. Typically, the results were written on little bits of paper, hand-copied into larger sheets or forms, and hand-copied again onto still-larger ledgers or record books that were kept in locked file rooms. The ledgers used by the
Children's Fund of Michigan for their biochemical determinations would have delighted Jacob Marley and Ebenezer Scrooge.

Readying the data for statistical analysis required additional copying in preparation for computational steps that involved more hand work and electromechanical calculators. At the Fels we were fortunate in the services of a statistical clerk who presided over a battery of Monroe calculators. Mary David would operate one Monroe until it began to smoke and then transfer her work to another.

The advent of computers opened new opportunities in growth-data analysis and the ability to resolve questions we had never dared to pose before. When we acquired an early N.C. R. computer at the Fels, I conceived of the notion of calculating the entire matrix of ossification timing correlations for 79 postnatal ossification centers, or 3,081 correlations for each sex. Then I proceeded to ascertain the principles that linked homologous and nonhomologous ossification centers in developmental timing, looking to propinquity, distance, and other anatomical variables for simple rules or generalizations.

Roy Acheson, then at Yale, expressed his admiration at my good fortune in having access to so large a radiographic collection and a big new computer to complete the thousands of correlations, the rankings, and the "communalities." W. W. Howells also granted the computer miracle and indicated pleasure at my intuitive attempt to make developmental sense out of 6,162 ossification correlations in all. "Congratulations," wrote Bill Howells, "you have just invented Factor Analysis!"

Today we often enter growth data right at the terminal, or even on-line from digitizers of various kinds. Clyde Owings at the University of Michigan developed computer-interfaced calipers that display results directly on the terminal against a computer-sorted spectrum of probable values. With available equipment and a TEXTEDIT program, measurements can be converted directly into hard-copy tables, ready for publication, without using a scrap of paper at all. The edited Denver growth data are available on tape, and so are the NHANES I growth variables.

\section{PUTTING IT ALL TOGETHER}

Bill Krogman wrote repeatedly and often about "the growth of the whole child," a notion that appealed to the people in growth studies and that was especially attractive to the lay. man. Finally, it seemed, growth investigators had it all together, investigating the whole child instead of disjuncted bits and pieces. But 
the transition from the grand concept of the growth of the whole child to the synthesis proved elusive and there were those who claimed (as did James N. Spuhler) that the growth of the whole child at best included one or two more parameters than had been investigated in earlier times!

Al Washburn, at Denver, employed the device of the clinical conference, bringing together the separate growth investigators to share their information and their findings about the growth of particular children. Harold Stuart, at Harvard, saw a good idea, realized its clinical origins, and scheduled such clinical conferences from time to time. So Veikko $O$. Hurme provided information on tooth eruption, C.F.A. Moorrees summarized his findings on occlusal development, I provided descriptive information on changes in physique, Bertha Burks summarized the dietary findings, and so it went. Each with our little speeches, we added our contributions. It took half a day, yet, the growth of the whole child proved elusive. We could say that Johnnie or Mary tended to be a bit advanced in some respects, on the average or behind in other sespects, and it was difficult to see causal connections and direct relationships even to known periods of disease.

Years later, one of the Fels parents (who had a background in animal genetics) made suggestions to me that had direct bearing on the whole-child problem. As he saw it, it was necessary to go back a generation, to the parents, using the kind of design common in animal genetics and to look for differences-during growth and development-in the children of different parental combinations. It was not only intriguing to set up parental size combinations Large $\times$ Large, Small $\times$ Small, Small $\times$ Large, etc., but it was more intriguing to compare the growth and development of maturational timing of the children so identified. Large $\times$ Large not only tended to yield large children, but children advanced in growth and development and higher caloric intake and advanced in behavioral and cognitive as well as dimensional respects.

Taking the parental combination Large $X$ Large (using the bony-chest breadth as a direct measure) results were even more dramatic for the Bayley, Merrill-Palmer, and early Binet scores than they were for stature and weight alone. Children of parents with a large FatFree Weight tended to be advanced in I.Q. through 12 years of age and advanced or ahead in many other respects.

So it is possible to "put it all together," to approximate more nearly the idealized "growth of the whole child," but there must be a direction to start with-parental size (as mentioned above) or maturational timing. As we have since discovered, the sons and daughters of early-maturing mothers tend to be bigger earlier and fatter, they tend to be early maturing themselves (especially the sons) but slower in postmaturational time. Conversely, the girls and boys of late-maturing mothers tend to be smaller earlier but larger later and behavioral scores reflect heirarchical or lawful differences in developmental timing. But it remains to be seen what growth-controlling mechanisms synchronize size and physical development and various measures of behavioral development, altogether.

\section{FROM THE PAST TO THE FUTURE OF GROWTH}

Forty years ago physical anthropologists were so unaware of growth that they grouped all people from 17 to 70 as "adults." They were so unaware of the implications of nutrition for growth and development that differences between populations were often viewed as exclusively "genetic" in origin. They were so unaware of dimensional and developmental changes over time that differences between generations and over the centuries were somehow viewed as necessarily "evolutionary."

Contributions of human growth studies have changed these views and these attitudes. What we know now about the secular trend and shrinkage, together, has made for narrower age intervals in our investigation. What we know now about nutritional influences on growth and size and maturation make us less likely to attribute differences to differences in gene frequencies. We know enough now about environmental changes so that differences among archaeological populations are not necessarily set forth as proof of ongoing human evolution.

In such ways grow th has become much more a part of physical anthropology and most physical anthropologists now have a much broader appreciation of growth. Besides (as pointed out earlier in this chapter) the limits of growth research have also expanded. Were he alive today Hooton would no longer press his old objection to growth studies. Studies that simply describe size comparisons of populations as if they were describing a horse race are far less common today.

Despite D'Arcy Wentworth Thompson, despite Julian Huxley, and despite Peter Medawar, studies of growth and form did not come easily to students of man, many of whom use the double-log plot as a kind of magic. But with computer graphics now we can make grid 
magic and with computer programs we can genuinely study growth and form. Half a dozen groups interested in craniofacial growth can now project facial growth right at the terminal, using canned data.

It is fashionable to speak of control mechanisms of growth (in more than the statistical sense) and beyond the sage statement that part is nutritional and part is of environmental origin. With somatotropin and somatomedin we are closer to one or two control mechanisms of growth. Much further away are still the questions of how genes build faces, what turns growth off, and (even) why cells grow. Questions like these were beyond the possibilities of investigation in earlier times of growth research; they are not beyond question now. When we consider that programmed cellular death is responsible for segmentation, for the blanking out of round bones, and for differentiation from the limb buds, the nature of programmed cellular death becomes both intriguing and exciting, as are the implications of death to life.

Growth and development do not exist in temporal caskets. There is no period of growth (that covers all tissues and organs), no period of maturity (for all tissues and organs), and no period of aging that holds equal meaning for every tissue and every organ. Even the concepts of growth and development and maturity will have to change and the terms themselves may cease to be used as we discover the exceptions that make these terms too simplistic for continued use.

If growth is an increase in the number of cells, and if increase in fatness is therefore growth, what word describes the decrease in adipocyte number if not size. With age, and decrease in body mass, there is an attenuation in the number of cells. There may be a decrease in the size of cells as well as a decrease in their life-span and their rates of replacement. With age there must certainly be a decrease in the size of some cells.

Questions such as these are within our power to answer as well as questions of more traditional and familiar form. Will generations of prosperity erase the smaller body size of Japanese to the point where they exceed most Europeans in stature? However unbelievable this proposition, note that Roman school children exceeded the English (Tanner) norms by 1978 .

We have become familiar with the secular trend that had changed not only size but proportion. Our children are not only that much bigger in hand and foot than our parents were. They look different as well. It is not just change in fashion that gives today's women of the screen a face longer than Lillian Gish or Clara Bow: Faces have changed much since Susan B. Anthony and Carrie Nation. And yet is is not simply because they are bigger that they differ in face and hand. People are not the same over the generations even simply matched for size. If this be allometry, let us make more of it.

With increasing numbers of fossils whose taxonomic affinities exceed the available data, there are many differences in growth and development that we have opportunity to study and over time periods extending backward by millions of years. These fossil remains demand more than anthropometers and tapes to measure them and similar problems demand similar instruments in studies of more contemporary man. Radiography, film-type, is being joined by the CAT scanner with its potentiality for in-vivo body composition. Such technology and that of neutron activation open new opportunities to study morphogenesis, body composition, cell size, and turnover rates in the same individuals over different periods of time and under different circumstances. In fact, as we are beginning to learn, various kinds of environmental stress affect growth and replacement differently. It is with such direction in mind that we look to next generations of studies in human growth.

\section{A MYOPIC GLIMPSE INTO \\ THE FUTURE OF GROWTH}

The prototypical "growth" studies of the thirties and forties were longitudinal studies along the Berkeley/Boston/Brush/Denver/Fels model. Though growth norms and developmental standards were among their stated objectives, serendipity was a practical principle. The notion of seeing "how children grow" was a valid one, then and now, but data do not dance to every tune. People who are conscientious data collectors, careful as $\mathrm{H}$. V. Meredith was in assuring quality data year after year, are not necessarily best equipped to make breakthrough discoveries in human growth now. But great growth discoveries, such as the incredibly large individual changes in I.Q., are necessarily retrospective in nature, utterly dependent upon quality data collected years before by meticulous workers, yet analyzed well after the fact.

One by one the longitudinal growth studies lost core support for the continued collecting of repetitive data, though they gained interim finances for particular data collections and for specific analyses. In their stead, shorter-term and problem-oriented growth programs arose 
and prospered. The INCAP studies in Guatemala are one such example. The epidemiological studies (Bogalusa, Muscatine, and Tecumseh) are yet another. They continue the growth tradition, but in the context of cardiovascular disease. The National Collaborative Perinatal Project (NCPP), which followed its core group through 7 years, still lives in regional context, as with the Philadelphia contingent-now followed through adolescence and beyond. The National Aging Center in Baltimore has a longitudinal growth program, more than two decades old, the upper end of the womb-to-tomb lifelong approach.

There is no limit to growth studies of the special-purpose nature, as with twins in Indianapolis, or children of the once-starved Dutch mothers, or obese women in the Bronx. There are studies, long overdue, of Puerto Rican, Chicano, and Cubano children and (I hear) of the children of older and "elderly" parents who may be prone to Alzheimer's disease. As we come to discover the teratogens in our environment, there will be larger Love Canal studies, investigations of the children of chemical workers, and the children of drinking (and even alcoholic) women. Given the fitness ethic, it will be useful to follow the progeny of our jogging mothers. Given the drive to lastchance reproduction, and the generation of "snow blossom" babies, such boys and girls (like the progeny of teenage mothers) will soon attract special growth attention.

Federal support and philanthropic interest is unpredictable, yet "new" opportunities for growth research are inevitably about. It may be that our exchange of health-scientists with China will engender interest in the growth of Chinese-American children, renewing directions generated by Gabriel Lasker four decades ago. It may be that babies are again coming into vogue, making the White House conference of 1980 a call for new studies along the 1930-1950 line. It may be that the sample question "why children grow" will generate renewed interest in why small children are small, why large children are large, and whether growth regulating mechanisms can be reprogrammed to achieve the notion of "optional growth" that Krogman once held to be the natural right of every child. 